\title{
Dissociation of Colloidal Silver into lonic Form through Membrane under Electric Field
}

\author{
Kuo-Hsiung Tsenga*, Chih-Yu Liaoa, Der-Chi Tienb, and Tsing-Tshih Tsung ${ }^{b}$ \\ aDepartment of Electrical Engineering, NTUT \\ ${ }^{b}$ Graduate Institute of Mechanical and Electrical Engineering, NTUT \\ Taipei 10608, Taiwan, R.O.C.
}

\section{Introduction}

In this study, an electric dissociation system (EDS) for converting colloidal silver (CS) into ionic form through membrane under electric field has been proposed. More specifically, this study was undertaken in order to understand how the silver nanoparticle and ion exerts control over the electric field, and to suggest some theoretical as well as practical implication of this process. This technology will be used to develop a chemical residue-free administration of control-released medical device for iontophoretic application. It is well known that the silver ions can obtain by dissolving the silver salt, for instance, silver nitrate $\left(\mathrm{AgNO}_{3}\right)$, silver sulfate $\left(\mathrm{Ag}_{2} \mathrm{SO}_{4}\right)$, and silver chloride $(\mathrm{AgCl})$, in the aqueous medium. However, the counter-ion of silver salt such as nitrate $\left(\mathrm{NO}_{3}^{-}\right)$, sulfate $\left(\mathrm{SO}_{4}^{--}\right)$, and chloride $\left(\mathrm{Cl}^{-}\right)$may cause severe burns or toxicity to body when the silver ion has been consumed. Therefore, conversions of colloidal silver nanoparticles into ionic form are required, but not directly use the silver salts to provide the silver ions. This paper is structured as follows. In the first section of the article, we will start with an introduction to metallic silver and silver nanoparticles, and then present a short literature review of iontophoresis. The second section describes the experimental setup of the electric dissociation system (EDS). The third section summarizes the results and discussions for the various analyses of experimental data. Finally, conclusions are presented and suggestions are made for further research.

\subsection{Metallic silver}

Metallic silver has been known since ancient times and has long been valued as a precious metal, used to make ornaments, jewelry, currency coins, tableware, and utensils. Today, silver metal is widely used in conductors, switches, contacts, fuses and virtually all electrical appliances. Silver's role as an effective antimicrobial agent has been well established in several studies (Burrell et al., 1999; Thomas \& McCubbin, 2003). It can control a wide variety of yeast, fungi, and viruses (Thati et al., 2007). Human health care providers have used silver for diverse purposes for several thousand years (Goodman \& Gilman, 1975). Going back to Roman times, silver vessels has been used to preserve drinking water and other liquids fresh from bacteria. In the 18th century, immigrants tracking across America West found that if they placed silver coins in their casks of drinking water, it kept the water safe from 
bacteria and algae. In the early 1800s, doctors used silver sutures in surgical wounds with very successful results. In 1884, Credé proposed the use of drops of silver nitrate eye solution (1\% silver nitrate) to prevent ophthalmia neonatorum in newborns (Rungby, 1986). During World War I, silver foil was used to protect wounds from infection (Lewis, 1909). In the 1970s, the National Aeronautics and Space Administration (NASA) used silver containers to preserve the purity of drinking water (Metodiev \& Bozhilova, 1990) on spacecraft. These varied uses demonstrated the bacteriostatic properties of silver. However, at the beginning of the 20th century, the discovery and development of antibiotics has led to a dramatic reduction in deaths from infection. Thus, silver became less used for medicinal purposes. Over the last 50 years, widespread overuse of antibiotics has fueled a growing increase of antibiotic resistance among bacteria. For example, MRSA (methicillin-resistant Staphylococcus aureus) (Norrby et al., 2005) and VRSA (vancomycin-resistant Staphylococcus aureus) (Tenover, 2005) developed a strong outer wall that prevented antibiotics (penicillin) from penetrating and exerting its effects. But now, the growing ineffectiveness of traditional antibiotics and emergence of nanotechnology have renewed attention in the antibiotic properties of silver. As a result of the rapidly increasing growth of nanotechnology, silver grants a new prospect in 21st century. The development of nano-scale techniques is leading to a resurgence of interest in the medical use of silver.

\subsection{Silver nanoparticles}

The expression "nanoparticles" is, in general, used in the realm of materials science to represent particles size less than 100 nanometers, ranging between the molecular state and the bulk state. Within these nano-scales, materials in high surface-area-to-volume ratio will create their unique properties (Bawendi et al., 1990) in an extraordinary region, leading to novel and unexpected phenomena. In particular, metal nanoparticles such as silver nanoparticles have become an important target for modern chemistry, physics, and bioscience. Fabrication and characterization of silver nanoparticles has attracted considerable attention as a result of their significant applications in the fundamental sciences and nanotechnology. The potential applications of silver nanoparticles include catalysis (Sun \& Seff, 1994), photographic development processes (Huang et al., 1996), nanodetection (Park et al., 1999), electrodes for multi layer ceramic capacitors (MLCC), spectrally selective coating for solar energy absorption, and intercalation material for electrical batteries (Klaus-Joerger et al., 2001). Application of silver nanoparticles depends on the process used to manufacture particles with different size, shape, and chemical composition. Additionally, the products should be chemically and physically stable without undergoing degradation.

The silver nanoparticles suspended in solution as a colloidal suspension is a well-known bacteriostatic and poisonous agent for different bacteria and viruses (Lee et al., 2003). No side effects were observed when using drugs based on metallic nano-silver in clinical trials. Although, silver's exact antimicrobial mechanism is unknown yet. It has been determined, however, that the free silver ion is the active agent, with evidence that silver's antibacterial activity is directly proportional to the amount of silver ions released (Lansdown, 2006). These ions exhibit an oligodynamic effect by denaturing proteins in prokaryotic cells, typical of microorganisms (Feng et al., 2000). Mammalian cells are eukaryotic and so display a strong resistance to silver's effects, making the use of silver in treating human disease safe (Bicanová \& Thinschmidt, 1985). 
Several methods of silver nanoparticles fabrication exist. Current techniques used to produce silver nanoparticles are usually divided into chemical and physical methods. Reduction of metal ions into neutral metal clusters is a commonly used treatment in chemical synthesis. This includes conventional chemical (one- or two-phase system), photochemical (Huang et al., 1996), sonochemical (Zhang et al., 2004), electrochemical (Starowicz et al., 2006), and radiolytic reduction (Shin et al., 2008). From metal bulk samples are used to generate nanoparticles by physical methods include: lithography (Klein et al., 2008), evaporation (Korchagin et al., 2005), and laser ablation (Bae et al., 2002). Although these conventional methods may successfully produce silver nanoparticles, they require the use of stabilizers or surfactants to protect the silver particles against agglomeration (maintain a colloidal suspension), leaving these undesired chemicals in the solution after fabrication is complete. Additionally, these methods are usually expensive and potentially dangerous for the environment. In order to overcome the problems described above, a novel and easy method for the preparation of silver nanoparticles using the arc-discharge method (ADM) was presented.

The arc-discharge method (ADM) involves pulse direct current (DC) being passed through two silver electrodes which are submerged in deionized water. During discharge the temperature between electrodes can reach several thousand degrees Celsius and the Ag rods are etched in the water medium. Silver vapor condensed in water creates a well-dispersed and thermodynamically stable Ag aqueous suspension. Silver nanoparticles fabricated by ADM in water without any surfactants or stabilizers are characterized as a stable colloid, which can be stored in a glass container for a fairly long time at room temperature without visible sedimentation (no apparent precipitate). The ADM is a good alternative method for silver nanoparticles preparation, and is not only a relatively inexpensive process, but also environmentally friendly. Additionally, any experimental data obtained using these colloids can be confidently established, as there is no interference from any additional chemicals.

\subsection{Literature review of iontophoresis}

Iontophoresis is a non-invasive transdermal delivery technique, which allows introduction of various ions or other substance into the skin through the use of electricity. It could be considered as a suitable and effective alternative to conventional injection or oral administration. The iontophoresis technique has been developed and modified over the past 260 years. The first suggestions date from the mid 18th century, demonstrated an ongoing relationship between electricity and drug. In 1747, the Giovanni Francesco Pivati reported that the smell of Peruvian balsam preserved in a glass container turned into obvious in the room after connecting electrical source. In 1748, Giovanni Giuseppe Veratti had successfully treated patients with nervous diseases such as deafness, rheumatic afflictions, paralysis, and sciatic pain (Veratti, 1748). In 1800, Bernard Raymond Fabré-Palaprat was interpreted as proof for the electrically assisted transport of iodine ions through the body by using the compress soaked with potassium iodide (KI) and starch solution separately fixed on the both arm. A further significant milestone in the history of iontophoresis was the voltaic narcotism. In 1858, Benjamin Ward Richardson used tincture of aconitine, aconite extract and chloroform which has been used with the assistance of electric current for iontophoresis in dental anaesthesia practice. In the 1870s, the current mediated transport of matter through porous membranes or intact human skin had been extensively studied by the Hermann Musk. To explain his theory, he introduced strychnine hydrochloride into rabbits 
by means of electricity. After exposure to an electrified strychnine solution, spontaneous cramps were observed in the rabbits. In 1908, Leduc (Leduc, 1908) reported the medical use of iontophoresis for the transport of drugs into the body. He was aware that some chemicals under a direct current which could be carried across an avascular membrane as the transporting agent. The strychnine experiments were also performed by Leduc (Latham et al., 2003). In 1965, Rapperport (Rapperport et al., 1965) achieved a very high level of penicillin in eschar by using iontophoresis. In 1978 and 1980 iontophoresis was clinically used for the treatment of ear chondritis (LaForest \& Cofrancesco, 1978). Today, iontophoresis has wide variety of applications, including in ophthalmology, dermatology, ENT (ear, nose, throat), allergic conditions, furthermore in neurological diseases.

The basic components of transdermal iontophoresis consists of a battery, two oppositely charged electrodes, and drug reservoir, as shown in Figure 1. The drug in ionic form in communication with the permeable skin is very susceptible, due to the fact that each ion can be influenced under an electrical field effect formed within the solution. For instance, positively charged ions (cations) like silver will be attracted to the negative electrode (cathode) and repelled from the positive electrode (anode). The electrostatic repulsion of like charges will become the primary driving force for iontophoresis process. In mainly applications, the power source supplies a constant current. As the current drives the ions through the skin barrier walls, the electrical circuit is accomplished whereby the charged molecules. The iontophoretic system offers the following key benefits to improve quality of drug delivery and reduce potential complications. (1) Because the iontophoretic treatment is a non-invasive and simplified therapeutic regimen, it poses minimal tissue trauma, infection risk, and avoids the inconvenience of continuous intravenous infusion. (2) Drug solutions are directly transferred to the treatment or evaluation site without the disadvantage of oral administration. (3) It provides a relatively pain free alternative for patients who are unable or reluctant to receive injections. (4) The therapeutic efficacy can be enhanced due to the hepatic first-pass metabolism is bypassed. (5) Reduce the possibility of over- or underdosing by continuous drug release at the programmed rate. (6) Permit the administration of a drug with a short biological half-life.

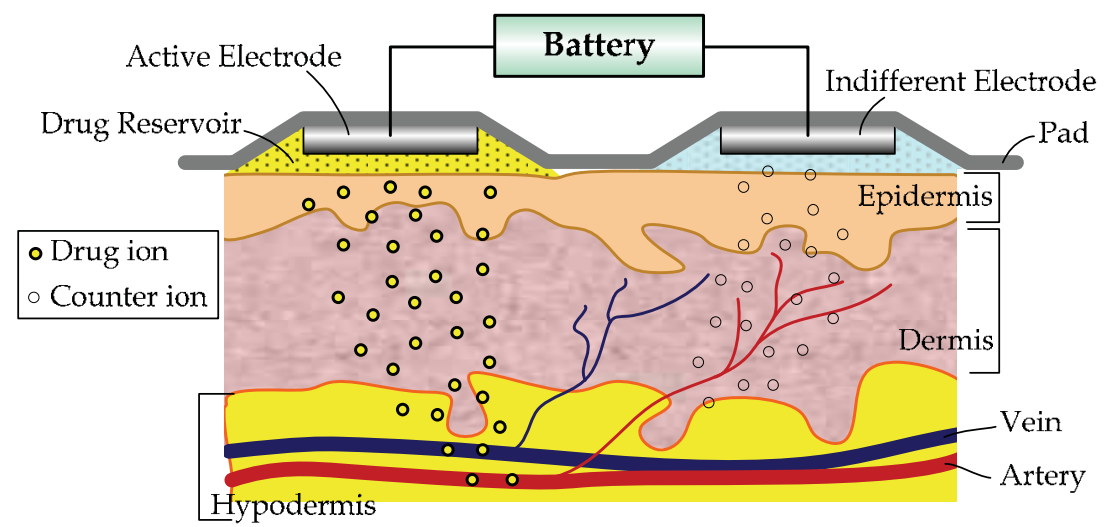

Fig. 1. Basic principle of iontophoresis 


\section{Experimental Methods}

\subsection{Preparation of the colloidal silver}

An arc-discharge method (ADM) is used to fabricate the colloid silver solution in present work. The ADM system, as indicated in Figure 2, consists of five main parts listed and described below: (1) Two silver electrodes (Gredmann, 99.99\%) $1 \mathrm{~mm}$ in diameter; (2) A servo control system which maintains a constant distance between the electrodes; (3) A power supply system connected to the electrode, which controls the DC arc-discharge parameters; (4) A glass container with an electrode holder and deionized water $(\mathrm{pH}=5.8$, conductivity $=0.8-0.9 \mu \mathrm{S} / \mathrm{cm}$ ) to collect the silver colloids; (5) A stirring system with magnetic stirrer and stirring bar.

The servo control system based on a feedback loop controls the gap between electrodes which is equal to a few microns $(20 \sim 40 \mu \mathrm{m})$. The glass container with deionized water is stirred by using the magnetic stirrer at room temperature. Silver wires are used as both the positive and negative electrodes. The upper Ag electrode is held by the servo control system and the bottom one is fixed by the electrode holder. The parameters of the control system were chosen for optimal conditions of Ag nanoparticles production.

The power supply system provides a stable pulse voltage of $70-135 \mathrm{~V}$ for $2-3 \mu$ s and then maintains a pulse of 20-40 V for around 7-8 $\mu$ s, in order to ionize the aqua medium between the Ag electrodes. In this moment, the etching current can reach $4 \mathrm{~A}$. Well-controlled timing on and off is demonstrated in Figure 3. The governing parameters of this system given in Table 1, such as the working voltage, selected current, pulse duration (on/off-time), electrode gap, and temperature of the deionized water are crucial factors for nanoparticles production. During the spark discharge, the surface layer of the Ag wires is evaporated and condensed in the water. The transparent solution converts to the characteristic pale yellow, and then a stable silver suspension is created. Calculation of the energy is required for system level energy consumption evaluation and optimization. The energy (E) in Joules is the product of the voltage $(\mathrm{V})$, the current $(\mathrm{I})$ and the time $(\mathrm{t})$. By recording this energy level, the corresponding amount of consumed electrode per energy used can be calculated. This in turn, gives information on amount of nanoparticles formed and solution concentration.

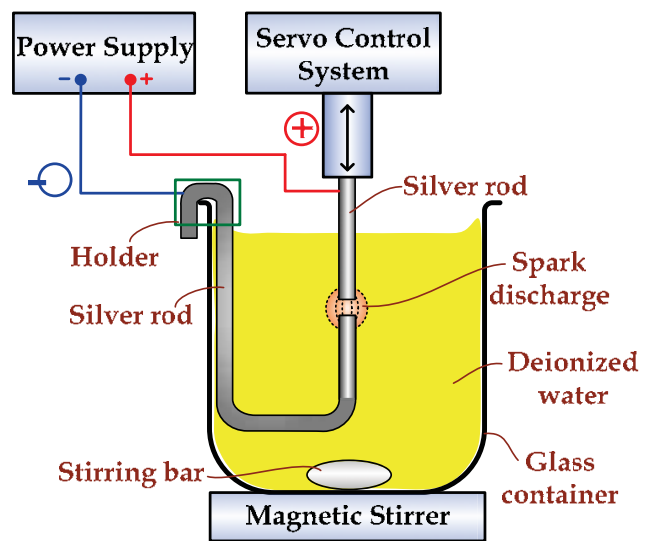

Fig. 2. Schema of the arc-discharge method for colloidal silver production 

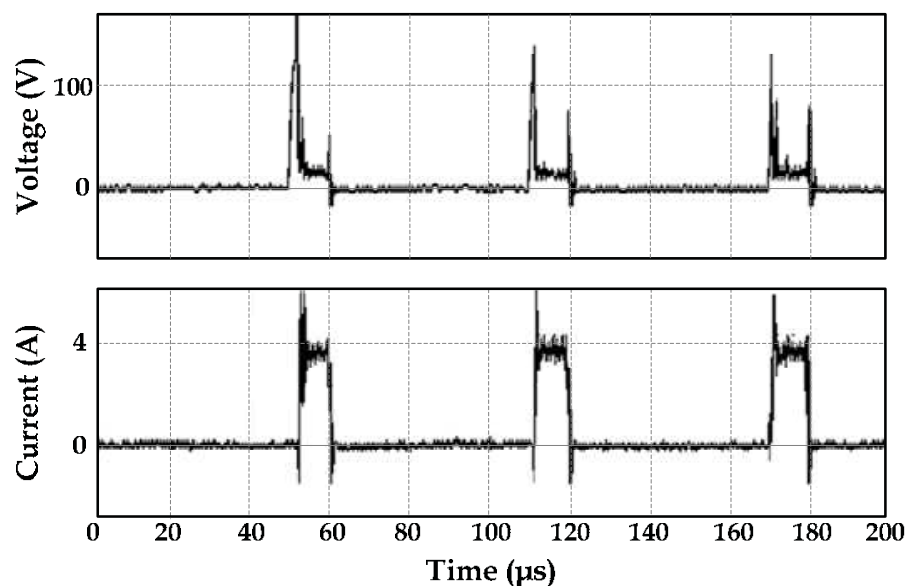

Fig. 3. Current and voltage pulses created by the ADM during etching of the silver electrodes

\begin{tabular}{|l|l|}
\hline Parameter & Value \\
\hline Fabrication pressure & $1 \mathrm{~atm}$ \\
\hline Fabrication time & $60 \mathrm{~s}$ \\
\hline Initial voltage & $135 \mathrm{~V}$ \\
\hline Off-pulse duration & $50 \mu \mathrm{s}$ \\
\hline On-pulse duration & $50 \mu \mathrm{s}$ \\
\hline Working current & $4 \mathrm{~A}$ \\
\hline Temperature of deionized water & $25^{\circ} \mathrm{C}$ \\
\hline Volume of deionized water & $500 \mathrm{~mL}$ \\
\hline
\end{tabular}

Table 1. Key parameters for silver nanoparticles suspension production

\subsection{Electric dissociation system setup}

The complete electric dissociation system (EDS) is shown in Figure 4. The system was performed using two glass bottles $\left(600 \mathrm{~cm}^{3}\right)$ positioned horizontally with a membrane between them, silicone rings to hold the bottles together, and platinum $(\mathrm{Pt})$ electrode wires (99.99\%, Gredmann). Inert Pt was chosen for both electrodes because it was resistant to reaction with the other elements involved and presents no toxicity to any situation. Colloidal silver solution with a yellow tint $\left(400 \mathrm{~cm}^{3}\right)$ was placed in the anodic chamber with the anode being mounted therein and submerged in the solution. On the other hand, the deionized water $\left(400 \mathrm{~cm}^{3}, \mathrm{pH}=6.5\right.$, conductivity $\left.=0.7 \mu \mathrm{S} / \mathrm{cm}\right)$ was placed similarly in the cathodic chamber with the cathode. Cellophane was selected as a membrane between the bottles, and its semi-permeability allows for ions to pass through, but not particles or large molecules. Magnetic spin bars were placed in the bottom of both bottles to ensure the homogeneity of the solutions, and eliminating the concentration variable when monitored by the measuring devices placed within the bottle. Lastly, a direct current (DC) power supply was used to provide constant-voltage $(\mathrm{CV})$ and constant-current $(\mathrm{CC})$ across the electrodes. 
The silver ion concentration and light absorbance of the two chambers were collected using, respectively, an ion selective electrode (ISE) and UV-Vis spectrophotometer. Ion selective electrode is a membrane electrode, which responds selectively towards one (or several) ion species in the presence of others, based on the thin membrane property to bind only the intended ion. For instance, the Ag ion selective electrode gives voltage when it is submerged in $\mathrm{Ag}^{+}$solution; the voltage is proportional to the ion concentration. A peristaltic pump circulated solution from the chamber to a UV-Vis double-beam spectrophotometer (Helios Alpha 9423UVA1002E) for continuous absorbance measurement during the entire course of the experiment. The spectrum was scanned from $190 \mathrm{~nm}$ to $600 \mathrm{~nm}$. The optical properties of a metallic nanoparticle depend mainly on its surface plasmon resonance (SPR), where the plasmon corresponds to the collective oscillation of the free electrons in the conduction band of Ag. According to the Mie theory (Mie, 1908), it is well known that the peaks, intensity, and line-widths of plasmon resonant are sensitive to the nanoparticle size (Tilaki et al., 2006), concentration (Eustis et al., 2005), shape (Sosa et al., 2003), metallic species (Mulvaney, 1996), and the surrounding medium (Kossyrev et al., 2005).

In this investigation, the parameters of EDS such as applied voltage and current were carried out for exploring the properties of this system in detail. A precisely regulated DC power supply can be used to provide either a constant-voltage or constant-current sources. A constant-voltage $(\mathrm{CV})$ source generates a DC voltage that can be set to any determined value in a specific range. On the other hand, a constant-current (CC) source produces a regulated current independent of the voltage over the entire chamber (up to the maximum allowable voltage). As a separate step in the experimental design, the different parameters of constant-voltage $(50 \mathrm{~V}, 100 \mathrm{~V}, 150 \mathrm{~V}, 200 \mathrm{~V})$ and constant-current $(100 \mathrm{uA}, 200 \mathrm{uA}, 400 \mathrm{uA}$, $600 \mathrm{uA}, 800 \mathrm{uA}$ ) have to be taken into consideration for estimating and optimizing the controlled release of silver ions. An interpretation of these experimental results outlining the main features and phenomena will be presented in detail below.

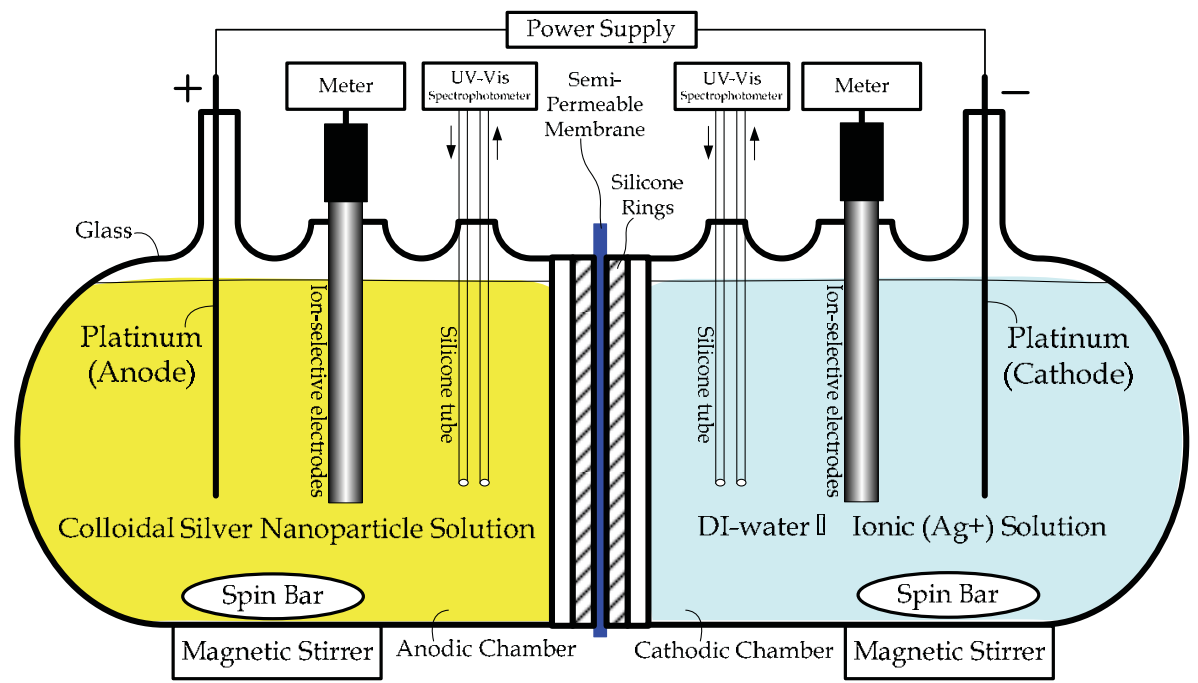

Fig. 4. Schematic of the electric dissociation system (EDS) 


\section{Results and Discussions}

\subsection{Characterization of the colloidal silver}

The field emission scanning electron microscope (FE-SEM, HITACHI S4700) was used to observe the size distribution and morphology of the silver nanoparticles. Figure 5 show representative SEM image and corresponding size distribution histograms of the $\mathrm{Ag}$ particles. As can be seen, a particle size below $30 \mathrm{~nm}$ is observed. A titrator (METTLER TOLEDO-DL50), to estimate the concentration of the ionic silver-using $\mathrm{NaCl}$ of a predetermined molar concentration that reacts with the ionic silver to form a precipitate, we can calculate the concentration of ionic silver in the colloidal silver (CS) solution. An atomic absorption spectrophotometer (AA, Shimadzu AA-680), to measure the concentration of ionic silver below the threshold of $6 \mathrm{ppm}$ in order to check the accuracy of the estimate made with the titrator. As shown in Table 2, the concentration of the ionic silver in the CS was $19.9 \mathrm{ppm}$ (Titrator) and $26.4 \mathrm{ppm}$ (AA). The measurement taken with the AA is greater than the measurement taken with the titrator because the AA is sensitive to both the ionic silver and the metallic silver nanoparticle, whereas the titrator is sensitive solely to the ionic silver. Using a centrifuge, it was able to separate the ions from the particles and to perform individual qualitative and quantitative analyses in an attempt to explore the nature of the ions. A centrifuge running at $18,000 \mathrm{rpm}$ for 100 minutes is then used to extract the ionic silver (which is contained in the supernatant $-\mathrm{Ag}^{+}$) and the metallic silver nanoparticles (which are contained in the sediment - $\mathrm{Ag}^{0}$ ). Because ionic silver dissolve only in the supernatant, therefore can determine silver ions concentration of CS through the use of Titration and AA. These gave us measurements of $18.6 \mathrm{ppm}$ and $19.2 \mathrm{ppm}$ respectively. After the sediment (Ag particles) dissolved fully in the nitric acid, the titrator and the AA gave measurements of $11.2 \mathrm{ppm}$ and $11.4 \mathrm{ppm}$ respectively. This suggests that the metallic silver nanoparticle suspended in the CS had a concentration of approximately $11 \mathrm{ppm}$.

\begin{tabular}{|c|c|c|c|}
\hline \multirow{2}{*}{$\#$} & Sample & Titrator & AA \\
\cline { 3 - 4 } & & $(\mathrm{ppm})$ & $(\mathrm{ppm})$ \\
\hline 1 & Colloidal silver & 19.9 & 26.4 \\
\hline 2 & Supernatant $\left(\mathrm{Ag}^{+}\right)$ & 18.6 & 19.2 \\
\hline 3 & Sediment $\left(\mathrm{Ag}^{0}\right)$ dissolved by $\mathrm{HNO}_{3}$ & 11.2 & 11.4 \\
\hline
\end{tabular}

Table 2. Measurement result of silver concentration 


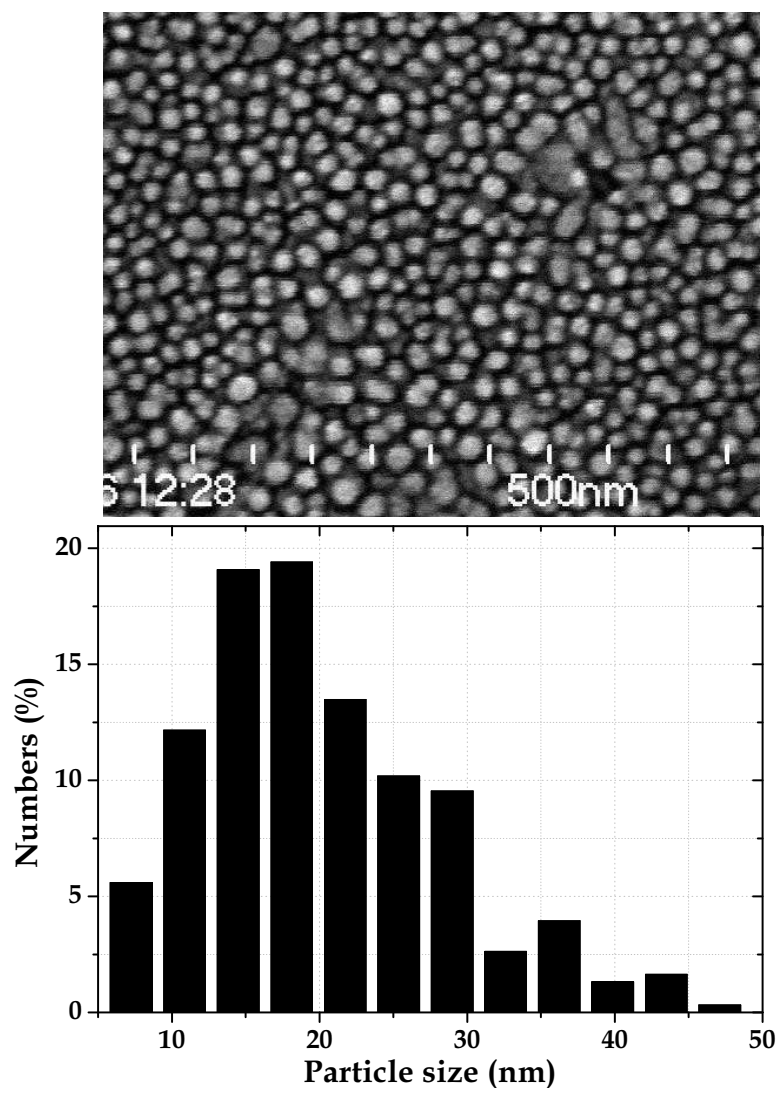

Fig. 5. (Upper panel) SEM image of silver nanoparticles; (lower panel) histogram of size distribution

\subsection{UV-visible light absorbance analysis}

The UV-visible light absorbance of the both chambers was spectrophotometrically determined detail of silver activity throughout the course of the experiment. Absorption peaks at around $396 \mathrm{~nm}$, characteristic of Ag nanoparticles (Badr et al., 2006), and at around $190 \mathrm{~nm}$, which is assumed to signify silver ions (Matsuoka et al., 2000), are seen in the anodic chamber as shown in Figure 6. These then decrease progressively in absorption peak with increasing time intervals (from 0 to $180 \mathrm{~min}$ ), indicating loss of both forms $\left(\mathrm{Ag}^{0} \& \mathrm{Ag}^{+}\right)$. A corresponding trend towards steadily increasing peak around $190 \mathrm{~nm}$ with the migration time in the cathodic chamber indicates the presence of only silver ions, as shown in Figure 7. The anodic chamber shows an unusual increase in absorbance around 435-550 $\mathrm{nm}$ region after 60 minutes as shown in Figure 6 . This is probably caused by some silver nanoparticle aggregation, due to lacking of $\mathrm{Ag}^{+}$in colloidal silver solution. These were visually observed as brown cloud forms billowing outward from the anode in the direction of the cathode. Van der Waal's force causes these to agglomerate together and take on the brown color 
indicative of high silver nanoparticles concentration. Eventually these dissociate into ions as well, contributing to the silver ion absorbance peak in the cathodic chamber.

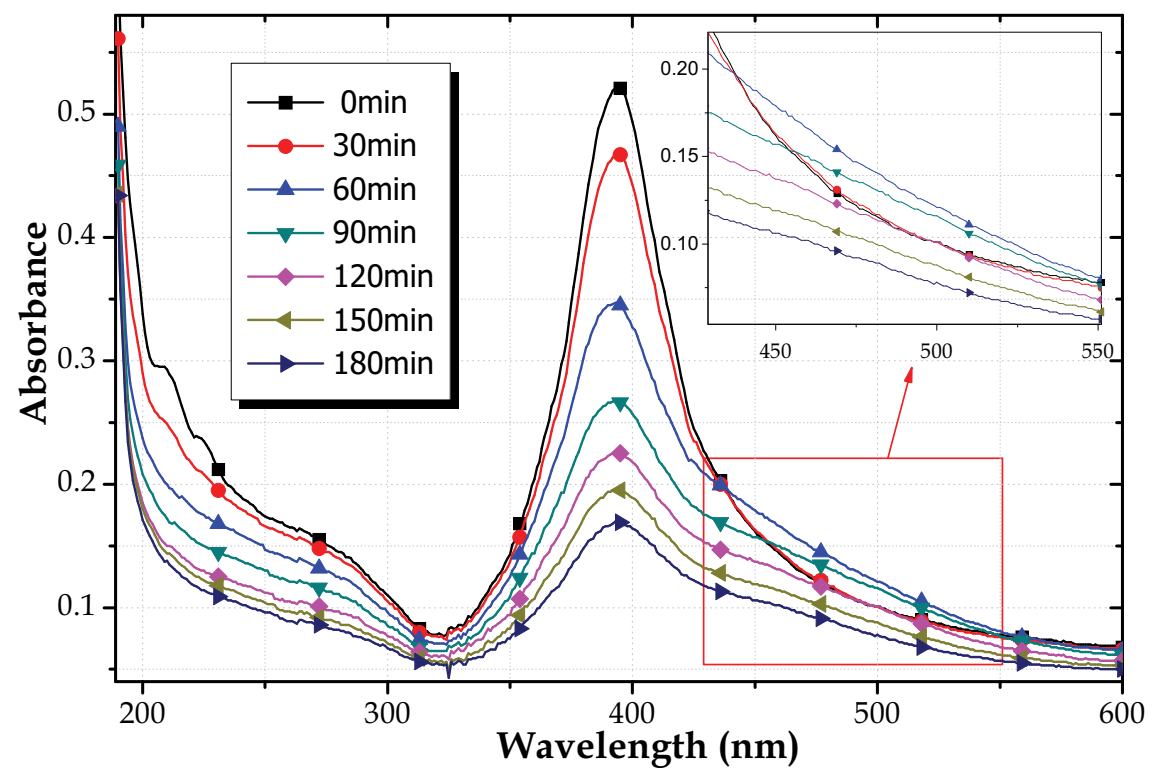

Fig. 6. Typical UV-Vis spectra of anodic chamber during process

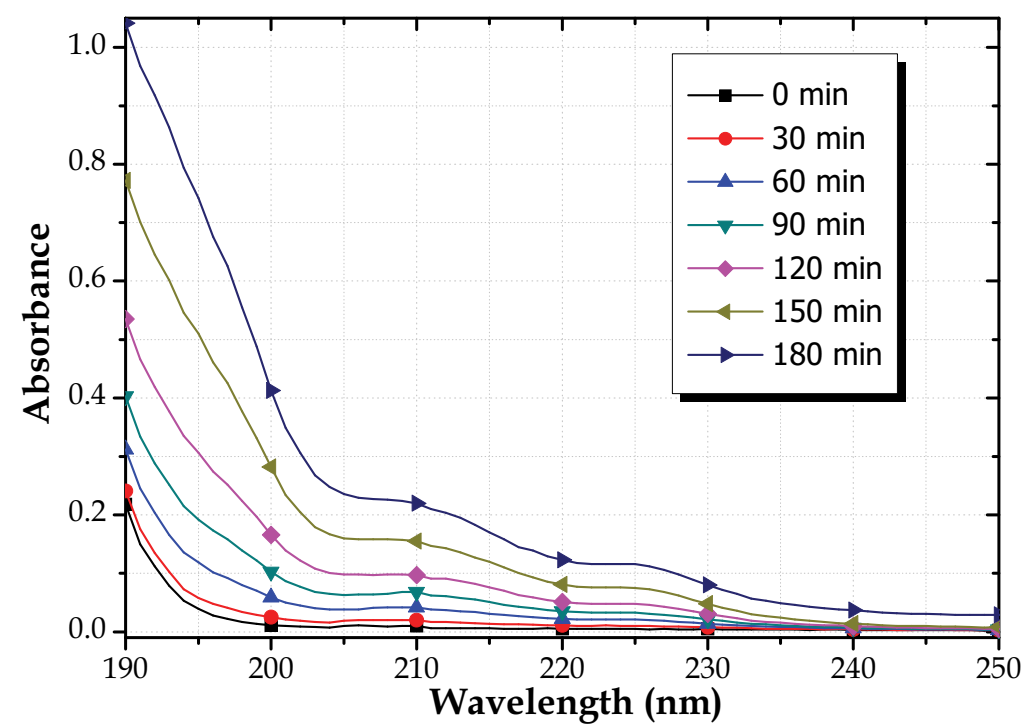

Fig. 7. Typical UV-Vis spectra of cathodic chamber during process 


\subsection{Time-concentration curve analysis}

To consider the processes of electric dissociation system (EDS), the $\mathrm{Ag}^{+}$concentration of both chamber have to be measured. Figure 8 illustrates a typical concentration-time profile of anodic and cathodic chamber of using ion-selective electrodes (ISE) to monitor the ionic silver concentration. As can be seen in this figure, the curve reflects two stages of different behaviour. In the stage 1 , the process begins when the anodic chamber concentration decreases as the ions move to the cathodic chamber. The cathodic chamber concentration is increased in the first three hours and then reaches a peak. After three hours (second stage), it slowly dropped due to the source of silver at anodic side is fully consumed. As time proceeds, the $\mathrm{Ag}^{+}$concentration will decline in the anodic chamber, rise to a maximum in the cathodic chamber, and then decline. It is important to note that the maximum cathodic ion concentration $\left(C_{\max }^{\text {cathodic }}\right)$ is not as same as initial anodic ion concentration $\left(C_{\text {initial }}^{\text {anodic }}\right)$ that depend on $\mathrm{Ag}^{+}$reduction rate dictated by the cathode. However, the changes in the anodic concentration quantitatively reflect changes in the cathodic. The AUC (area under curve) of both sides indicates that more ions reach the cathodic side than were initially present in the colloidal solution, due to the cathodic ions not only come from the anodic ions but also anodic dissociated Ag particle. However, most of ions in the cathodic side will quickly attach onto the cathode, and rapidly convert to atomic form. Finally, the steady-state $\mathrm{Ag}^{+}$ concentration gradient in the both chambers tend to zero and the solutions become diluted as water.

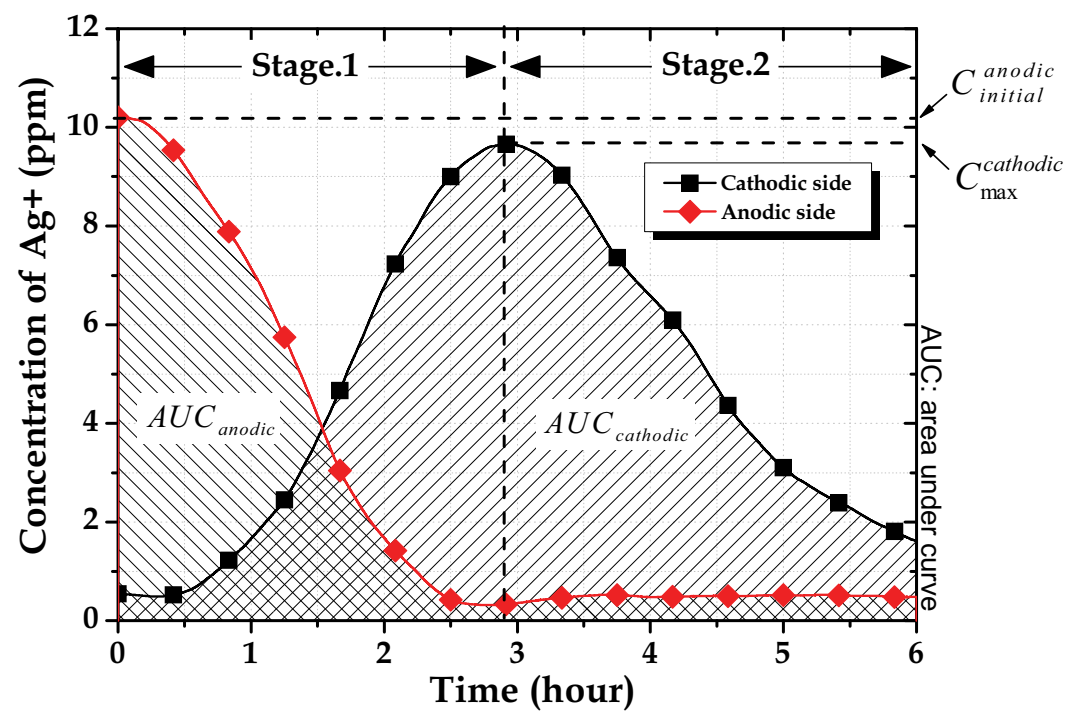

Fig. 8. Typical concentration-time profile (constant voltage 150V) of anodic and cathodic chamber 


\subsection{CV and CC effects on the properties of EDS}

The dissociation experiment tests in constant voltage (CV) mode increased from 50 to 250 VDC in $50 \mathrm{~V}$ steps had been achieved. All the initial conditions had been pre-determined throughout the entire course, such as the concentration and volume of colloidal silver, the distance between two electrodes, and stirring rate. The concentration-time profiles of anodic and cathodic chamber are shown in Figure 9 and Figure 10, respectively. As observed in Figure 9 (anodic side), it can be clearly found that the magnitude of the applied voltage will correlate with decline in silver ion concentration. That is, the higher the voltage is, the stronger the electric field will be, which will increase the silver consumption rate (ppm/hour). In addition, Figure 10 shows the voltage level will affect the area under curve (AUC), rate of rise and fall of profiles, total dissociation time, as well as the time required to reach peak concentration but not influence the peak level of concentration. The rate of rise is proportional to the ion-flow velocity that correlates to the number of silver ions through the semi-permeable membrane per unit time. The rate of fall indicates the speed of silver ions reduced into atoms by accepting an electron from negative pole. Consecutively, the peaktime was shown on the cathodic chamber, it regarded that the source of silver in anodic side was fully consumed at that particular point. According to the AUC, it can be seen that the lower applied voltage, the higher the AUC. Therefore, in the same initial conditions, a lower voltage can support large AUC with similar peak level of concentration provided by other voltage levels.

The dissociation experiment tests in constant current (CC) mode increased from 100, 200, 400,600 , and $800 \mathrm{uA}$ were also be explored. The experimental results of anodic and cathodic chamber are shown in Figure 11 and Figure 12, respectively. As observed in Figure 11, it can be found that the rise in iontophoretic currents led to an increase in ions transport rate and this effect became larger as the current was increased. These results are compared with results from the $\mathrm{CV}$ mode; the performance characteristics of two curves are similar. However, the driving force of ions is relative to the applied current, and as a result, the slope of decline on the anodic side in CC mode is more linear than in CV mode (variable current). Furthermore, Figure 12 shows that applied current can control more operating parameters, such as AUC, rate of rise and fall of profiles, total dissociation time, time required to reach peak, as well as the peak level of concentration. It was evident that the CC mode whether for research purposes or for solving practical problems has more freedom to optimize the performance, particularly in a medical environment.

The quantity of ion transported rate in anodic side and ion received rate in cathodic side for both kinds of modes are shown in Table 3. The release rate of anodic side and cathodic side are calculated by considering the fall- and rise-portion of the curve, respectively. The dissociation rate is a function of current; however, the current always changes over entire course in the $\mathrm{CV}$ mode. As a result, the dissociation rate in CC mode is regarded as more stable than that in $\mathrm{CV}$ mode. Thus, the maximum dissociation rate in $\mathrm{CV}$ mode and average dissociation rate in CC mode of both chambers are listed in this Table. The profiles of release rate versus voltage and current according to the Table 3 are shown in Figure 13 and Figure 14. Therefore, from the above experimental results, it can be inferred that the release concentration of silver ions can be programmed by controlling the magnitude of voltage or current. However, the CC mode is more controllable, due to the premeditated driving force is more precisely rely on the current not voltage. 


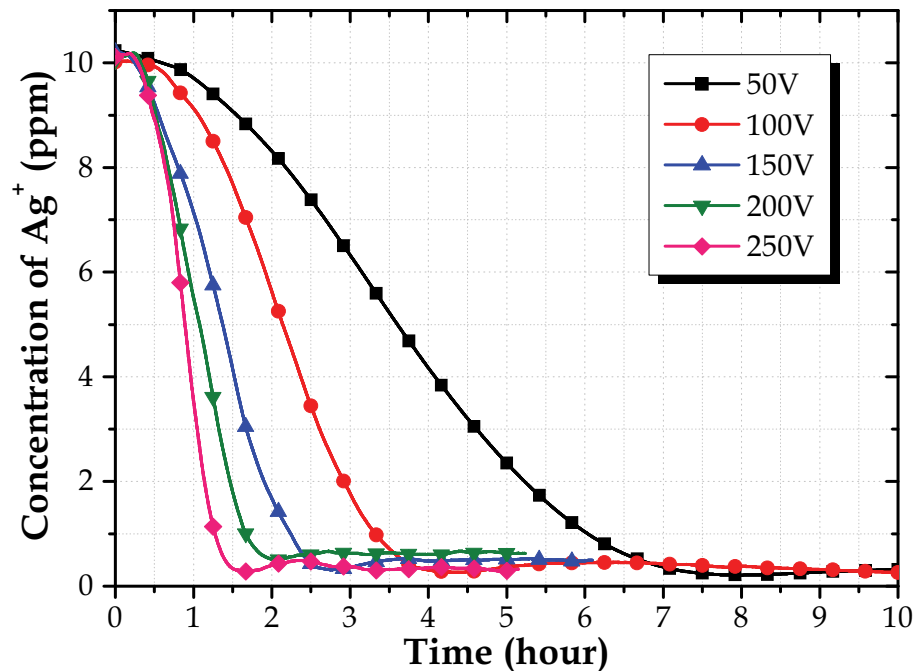

Fig. 9. CV mode (anodic side) - Curve of $\mathrm{Ag}^{+}$concentration versus time at difference voltage

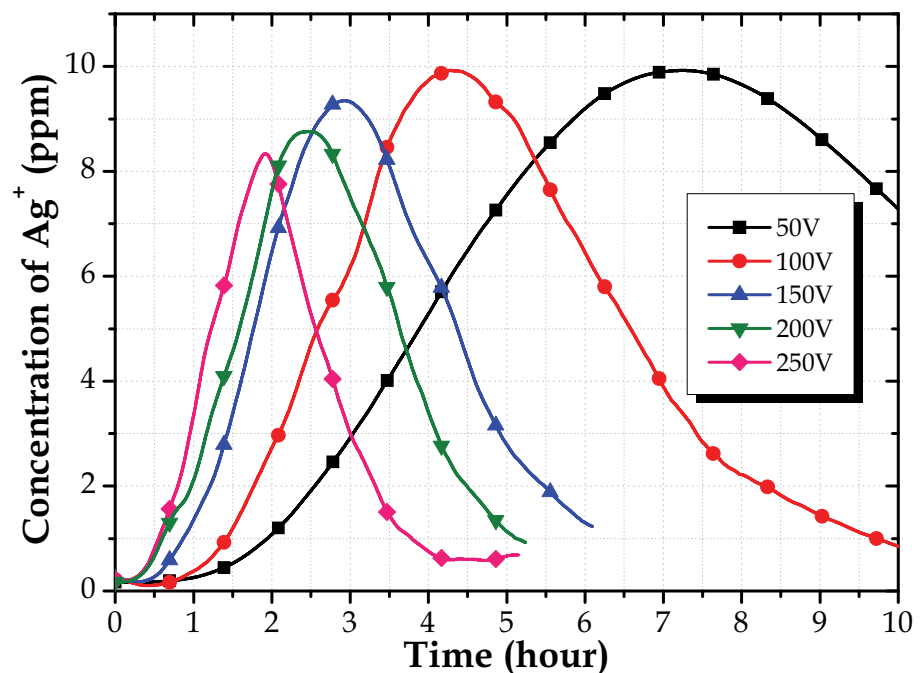

Fig. 10. CV mode (cathodic side) - Curve of $\mathrm{Ag}^{+}$concentration versus time at difference voltage 


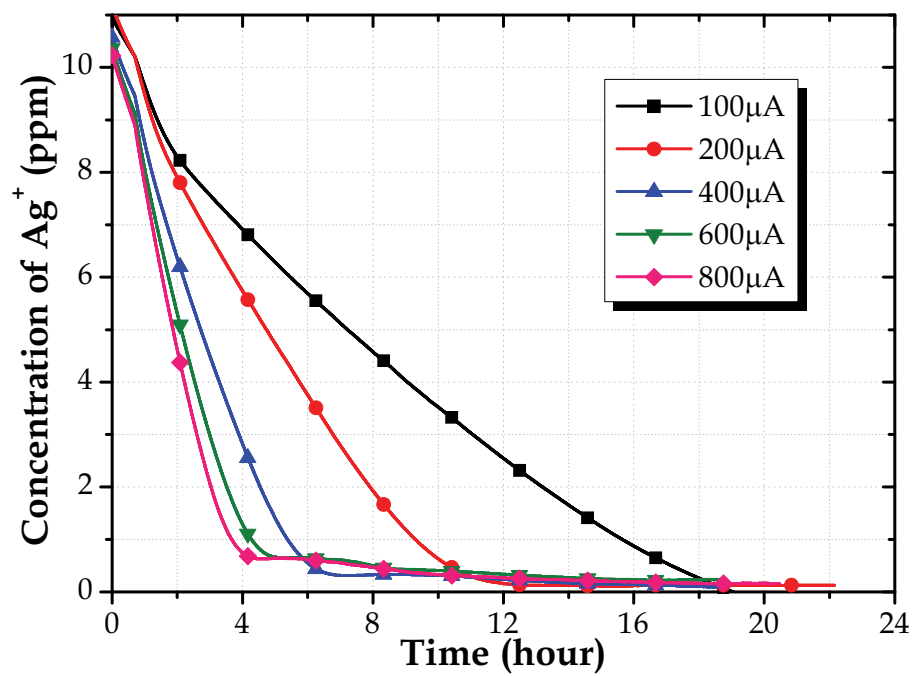

Fig. 11. CC mode (anodic side) - Curve of $\mathrm{Ag}^{+}$concentration versus time at difference current

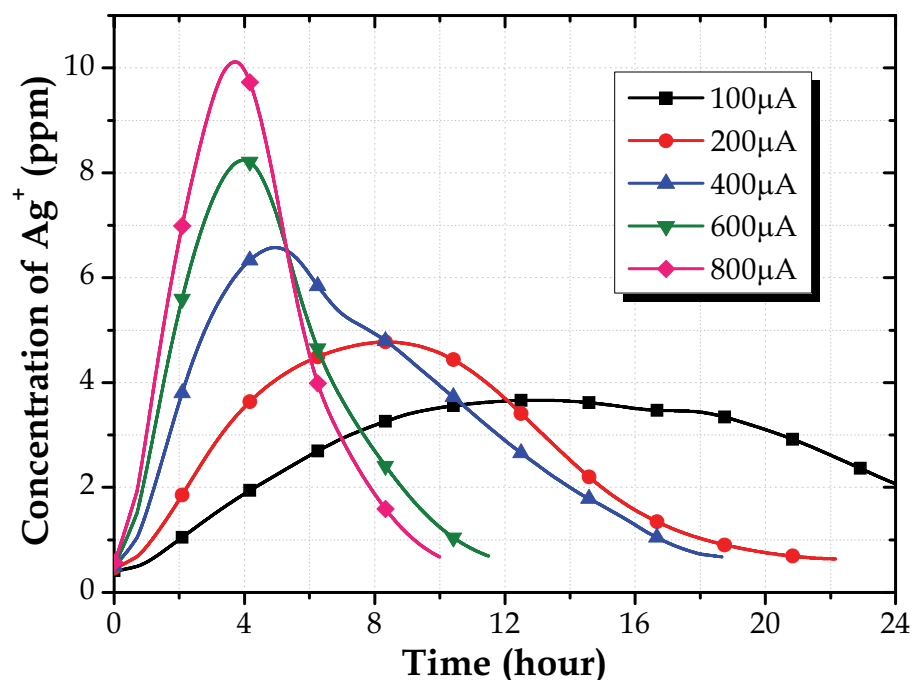

Fig. 12. CC mode (cathodic side) - Curve of $\mathrm{Ag}^{+}$concentration versus time at difference current 


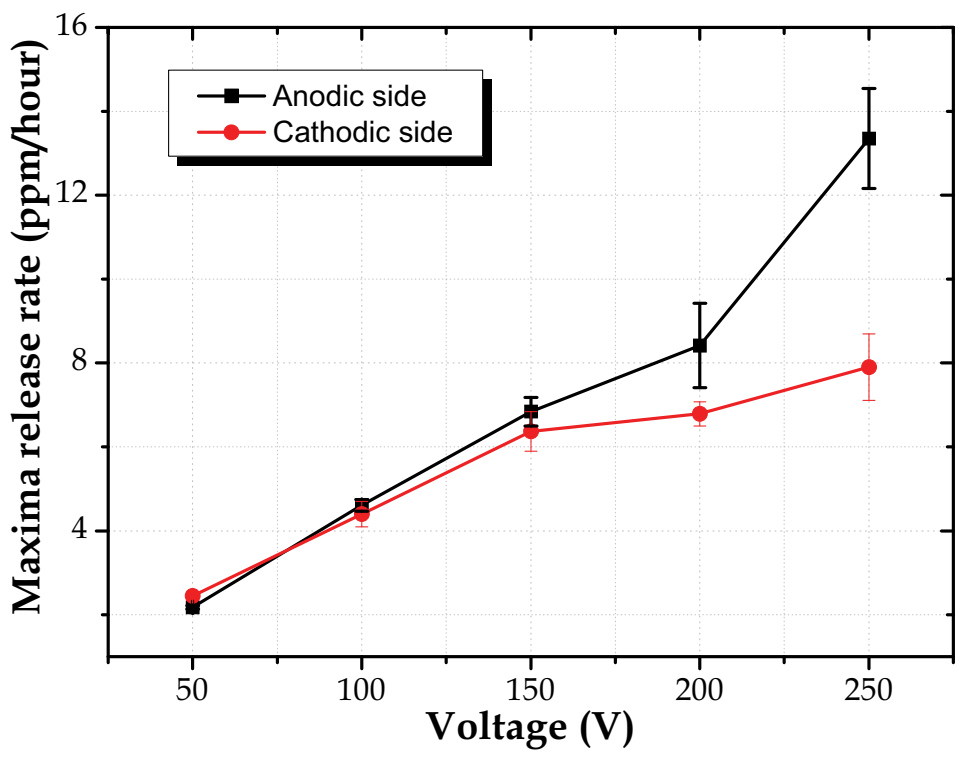

Fig. 13. Maxima ion release rate under different constant voltage

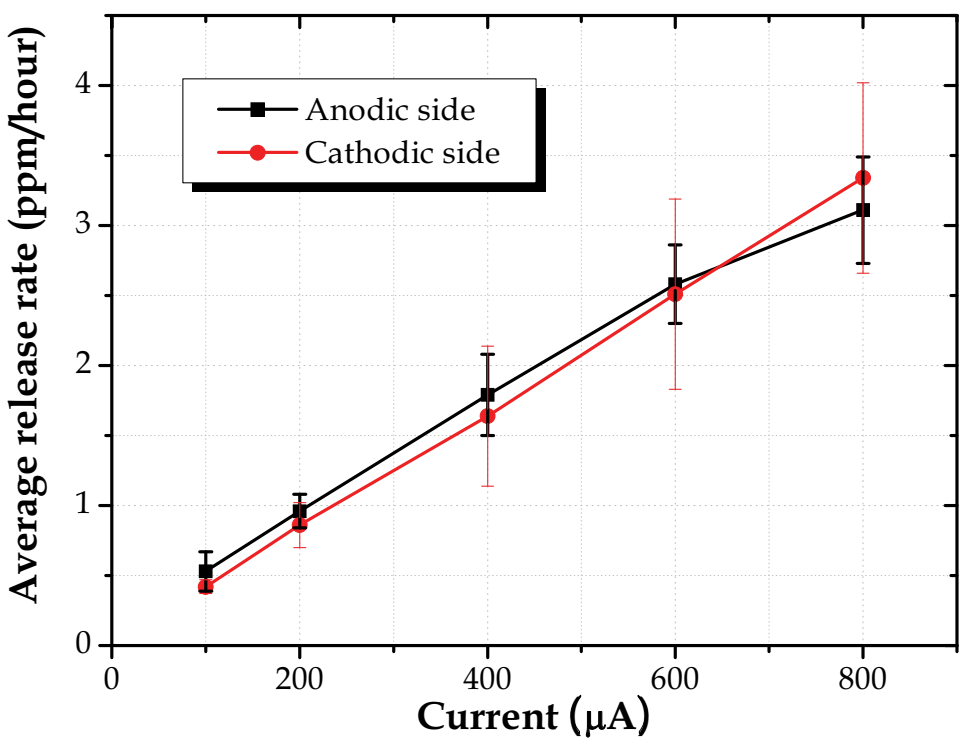

Fig. 14. Average ion release rate under different constant current 


\begin{tabular}{|c|c|c|}
\hline \multicolumn{3}{|c|}{ Maxima release rate in CV mode (ppm/hour) } \\
\hline Voltage $(\mathrm{V})$ & Anodic & Cathodic \\
\hline 50 & $2.18 \pm 0.04$ & $2.45 \pm 0.07$ \\
\hline 100 & $4.61 \pm 0.14$ & $4.40 \pm 0.30$ \\
\hline 150 & $6.84 \pm 0.34$ & $6.37 \pm 0.47$ \\
\hline 200 & $8.42 \pm 1.01$ & $6.79 \pm 0.29$ \\
\hline 250 & $13.35 \pm 1.19$ & $7.90 \pm 0.79$ \\
\hline Average release rate in CC mode (ppm/hour) \\
\hline Current $(\mu \mathrm{A})$ & Anodic & Cathodic \\
\hline 100 & $0.53 \pm 0.14$ & $0.42 \pm 0.05$ \\
\hline 200 & $0.96 \pm 0.12$ & $0.86 \pm 0.16$ \\
\hline 400 & $1.79 \pm 0.29$ & $1.64 \pm 0.50$ \\
\hline 600 & $2.58 \pm 0.28$ & $2.51 \pm 0.68$ \\
\hline 800 & $3.11 \pm 0.38$ & $3.34 \pm 0.68$ \\
\hline
\end{tabular}

Table 3. Ion release rate under different conditions

\subsection{Dissociation mechanism of colloidal silver}

Schematic illustration of the colloidal silver dissociation and migration process is illustrated in Figure 15. As soon as power is applied to the primary system (Figure 15a), the first commencement of process commences (Figure 15b). Here, existing $\mathrm{Ag}^{+}$are removed from the colloidal solution, as they move rapidly to the negatively charged cathode. Upon contact, the silver ions obtain an electron and convert to atomic form, as seen by the increasing formation of dendrites on the cathode (Figure 15c). In the next stage as demonstrated in Figure 15d, the silver nanoparticles dissociate into ionic form, and likewise migrate towards the cathode, finally leaving a water solution free of silver nanoparticles and ions in the anodic chamber (Figure 15e). In the end, both sides' solutions are turned into pure water as shown in Figure 15f. 


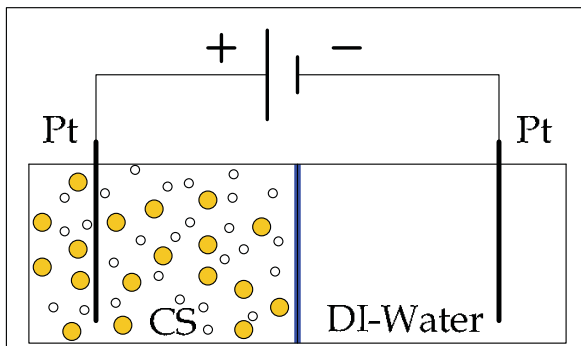

(a)
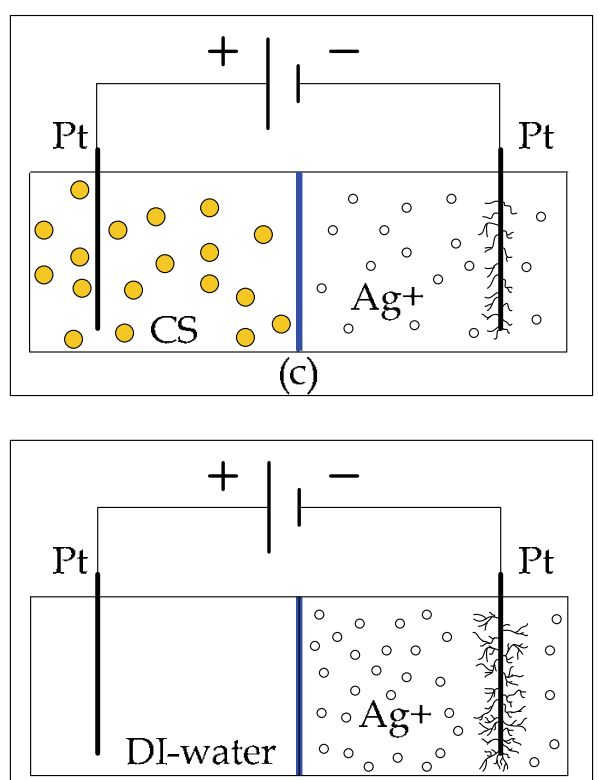

(e)

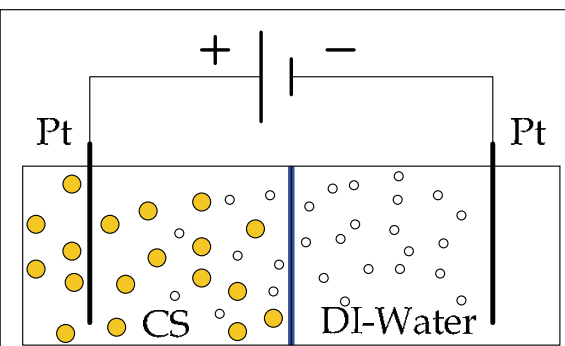

(a)

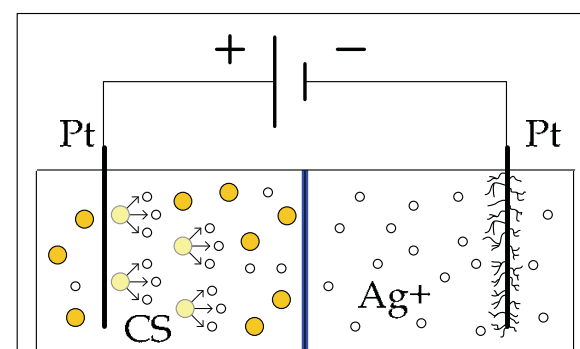

(d)

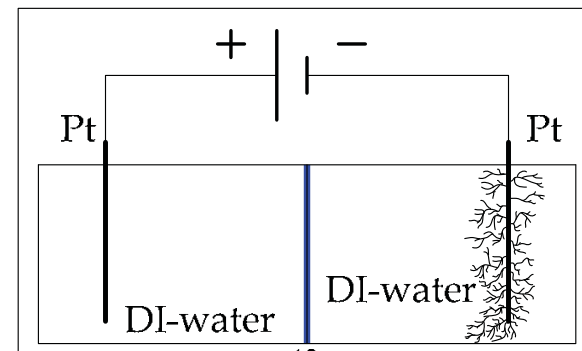

(f)

$\circ$ Silver Nanoparticle $\circ$ Silver Ion $\bigcirc \rightarrow \circ$ Nanoparticle Dissociation $*$ Silver Dendrites

Fig. 15. Schematic illustration of the colloidal silver dissociation and migration process, (a) initial system, (b)(c) existing $\mathrm{Ag}^{+}$are removed from the colloidal solution to the negatively charged cathode, (d) silver nanoparticles dissociate into ionic form and migrate towards the cathode, (e) the source of silver at anodic side is fully exhausted, (d) both sides' solutions are turned into pure water.

\section{Conclusion}

In recent years, there has been a dramatic proliferation of research related to the silver nanoparticle and ion. There is evidence indicating that the antibacterial potency of silver is directly proportional to the concentration of silver ions. Unfortunately, there have been no literature reviews or discussions concerned with the nano-silver suspension as a drug reservoir for iontophoretic application. For medical application, conversion of colloidal 
silver into ionic form are required, but not directly use the silver salts to provide the silver ions, due to the counter-ion of silver salt may cause severe problems to body as the silver ion has been consumed. The primary goal of this research is to develop a silver nanoparticles electric dissociation system (EDS) which can provide relatively safe silver ion solution with controllable electric field. In this study, the UV-visible spectroscopy and ionic selective electrode (ISE) were used to identify and observe details of the system activity. Both qualitative and quantitative data analyses were performed. The experimental results reveal that the release concentration of silver ions can be programmed by controlling the magnitude of electric power. These results are of great interest both for application and scientific research to develop a chemical residue-free administration of control-released medical device, and will open the doors for further study and application of silver ions. There are four advantages for getting the ionic form of silver via the colloidal solution.

1. The ionic silver is dissociated from metallic silver and will be no interference of counter-ion, as compared with silver salts dissolved in aqueous solution.

2. Under the same power condition, the silver nanoparticle, due to its large surface area per unit mass, may have a higher dissociation rate and efficiency than bulk metal. Thus, it can be drive at lower power for releasing silver ions.

3. Silver nanoparticles suspension prepared by arc-discharge method (ADM) without adding any conventional chemical surfactants is stable and non-toxic, thus there would be no chemical residue after the dissociation process.

4. An electric dissociation system (EDS) exploited in this paper that permits more controllable release rate of silver ion by an electric field for the potential future iontophoretic application.

Future study of this entire process could be integrated into a wound dressing. Its performance is dependent on a continuous controlled rate of silver ion release, which could be achieved by monitoring the current level and using a feedback loop to adjust voltage accordingly.

\section{References}

Badr, Y.; Wahed, M. G. A. E. \& Mahmoud, M. A. (2006). On 308 nm photofragmentation of the silver nanoparticles. Applied Surface Science, Vol. 253, No. 5, pp. 2502-2507, ISSN 0169-4332

Bae, C. H.; Nam, S. H. \& Park, S. M. (2002). Formation of silver nanoparticles by laser ablation of a silver target in $\mathrm{NaCl}$ solution. Applied Surface Science, Vol. 197-198, pp. 628-634, ISSN 0169-4332

Bawendi, M. G.; Steigerwald, M. L. \& Brus, L. E. (1990). The quantum mechanics of larger semiconductor clusters ("Quantum dots"). Annual Review of Physical Chemistry, Vol. 41, No. 1, pp. 477-496

Bicanová, M. \& Thinschmidt, G. (1985). Oligodynamic action of silver ions on microorganisms. Pharmazie, Vol. 40, No. 10, pp. 736, ISSN 0031-7144

Burrell, R. E.; Heggers, J. P.; Davis, G. J. \& Wright, J. B. (1999). Efficacy of silver-coated dressings as bacterial barriers in a rodent burn sepsis model. Wounds, Vol. 11, No. 4, pp. 64-71, ISSN 10447946 
Eustis, S.; Krylova, G.; Eremenko, A.; Smirnova, N.; Schill, A. W. \& El-Sayed, M. (2005). Growth and fragmentation of silver nanoparticles in their synthesis with a fs laser and CW light by photo-sensitization with benzophenone. Photochemical $\mathcal{E}$ Photobiological Sciences, Vol. 4, No. 1, pp. 154-159

Feng, Q. L.; Wu, J.; Chen, G. Q.; Cui, F. Z.; Kim, T. N. \& Kim, J. O. (2000). A mechanistic study of the antibacterial effect of silver ions on Escherichia coli and Staphylococcus aureus. Journal of Biomedical Materials Research Part A, Vol. 52, No. 4, pp. 662-668, ISSN 1552-4965

Goodman, L. S. \& Gilman, A. (1975). The pharmacological basis of therapeutics, Macmillan Publishing Co., New York, NY

Huang, H. H.; Ni, X. P.; Loy, G. L.; Chew, C. H.; Tan, K. L.; Loh, F. C.; Deng, J. F. \& Xu, G. Q. (1996). Photochemical formation of silver nanoparticles in poly(Nvinylpyrrolidone). Langmuir, Vol. 12, No. 4, pp. 909-912

Klaus-Joerger, T.; Joerger, R.; Olsson, E. \& Granqvist, C.-G. (2001). Bacteria as workers in the living factory: metal-accumulating bacteria and their potential for materials science. Trends in Biotechnology, Vol. 19, No. 1, pp. 15-20, ISSN 0167-7799

Klein, M. F. G.; Hein, H.; Jakobs, P.-J.; Linden, S.; Meinzer, N.; Wegener, M.; Saile, V. \& Kohl, M. (2008). Electron beam lithography of V-shaped silver nanoantennas. Microelectronic Engineering, Vol.In Press, Corrected Proof, ISSN 0167-9317

Korchagin, A. I.; Kuksanov, N. K.; Lavrukhin, A. V.; Fadeev, S. N.; Salimov, R. A.; Bardakhanov, S. P.; Goncharov, V. B.; Suknev, A. P.; Paukshtis, E. A.; Larina, T. V.; Zaikovskii, V. I.; Bogdanov, S. V. \& Bal'zhinimaev, B. S. (2005). Production of silver nano-powders by electron beam evaporation. Vacuum, Vol. 77, No. 4, pp. 485-491, ISSN 0042-207X

Kossyrev, P. A.; Yin, A.; Cloutier, S. G.; Cardimona, D. A.; Huang, D.; Alsing, P. M. \& Xu, J. M. (2005). Electric field tuning of plasmonic response of nanodot array in liquid crystal matrix. Nano Letters, Vol. 5, No. 10, pp. 1978-1981

LaForest, N. T. \& Cofrancesco, C. (1978). Antibiotic iontophoresis in the treatment of ear chondritis. Physical Therapy, Vol. 58, No. 1, pp. 32-4, ISSN 0031-9023

Lansdown, A. B. (2006). Silver in health care: antimicrobial effects and safety in use. Current Problems in Dermatology, Vol. 33, pp. 17-34, ISSN 1421-5721

Latham, R.; Linford, R. \& Schlindwein, W. (2003). Pharmaceutical and medical applications of polymer electrolytes. Ionics, Vol. 9, No. 1, pp. 41-46

Leduc, S. (1908). Electronic ions and their use in medicine, Rebman, London

Lee, H. J.; Yeo, S. Y. \& Jeong, S. H. (2003). Antibacterial effect of nanosized silver colloidal solution on textile fabrics. Journal of Materials Science, Vol. 38, No. 10, pp. 2199-2204

Lewis, J. S. (1909). IX. Note on silver foil in surgery. Annals of Surgery, Vol. 50, No. 4, pp. $793-$ 6, ISSN 0003-4932

Matsuoka, M.; Ju, W.-S. \& Anpo, M. (2000). Photocatalytic decomposition of N2O into N2 and $\mathrm{O} 2$ on the silver(I) ion-exchanged ZSM-5 catalyst. Chemistry Letters, Vol. 29, No. 6, pp. 626-627

Metodiev, V. \& Bozhilova, N. (1990). The effect of electrochemical silver on the microbiological qualities of drinking water. Problemi na Khigienata, Vol. 15, pp. 2630, ISSN 0323-9179

Mie, G. (1908). Beiträge zur optik trüber medien, speziell kolloidaler metallösungen. Annalen der Physik, Vol. 330, No. 3, pp. 377-445, ISSN 1521-3889 
Mulvaney, P. (1996). Surface plasmon spectroscopy of nanosized metal particles. Langmuir, Vol. 12, No. 3, pp. 788-800

Norrby, S. R.; Nord, C. E. \& Finch, R. (2005). Lack of development of new antimicrobial drugs: a potential serious threat to public health. The Lancet Infectious Diseases, Vol. 5, No. 2, pp. 115-119, ISSN 1473-3099

Park, S.-H.; Im, J.-H.; Im, J.-W.; Chun, B.-H. \& Kim, J.-H. (1999). Adsorption kinetics of Au and Ag nanoparticles on functionalized glass surfaces. Microchemical Journal, Vol. 63, No. 1, pp. 71-91, ISSN 0026-265X

Rapperport, A. S.; Larson, D. L.; Henges, D. F.; Lynch, J. B.; Blocker, T. G., Jr. \& Lewis, R. S. (1965). Iontophoresis. A method of antibiotic administration in the burn patient. Plastic and Reconstructive Surgery, Vol. 36, No. 5, pp. 547-52, ISSN 0032-1052

Rungby, J. (1986). The silver nitrate prophylaxis of Credé causes silver deposition in the cornea of experimental animals. Experimental Eye Research, Vol. 42, No. 1, pp. 93-94, ISSN 0014-4835

Shin, J.; Kim, Y.; Lee, K.; Lim, Y. M. \& Nho, Y. C. (2008). Significant effects of sodium acetate, an impurity present in poly(vinyl alcohol) solution on the radiolytic formation of silver nanoparticle. Radiation Physics and Chemistry, Vol. 77, No. 7, pp. 871-876, ISSN 0969-806X

Sosa, I. O.; Noguez, C. \& Barrera, R. G. (2003). Optical properties of metal nanoparticles with arbitrary shapes. The Journal of Physical Chemistry B, Vol. 107, No. 26, pp. 6269-6275

Starowicz, M.; Stypula, B. \& Banas, J. (2006). Electrochemical synthesis of silver nanoparticles. Electrochemistry Communications, Vol. 8, No. 2, pp. 227-230, ISSN 1388-2481

Sun, T. \& Seff, K. (1994). Silver clusters and chemistry in zeolites. Chemical Reviews, Vol. 94, No. 4, pp. $857-870$

Tenover, F. C. (2005). The real vancomycin-resistant Staphylococcus aureus has arrived. Clinical Microbiology Newsletter, Vol. 27, No. 5, pp. 35-40, ISSN 0196-4399

Thati, B.; Noble, A.; Rowan, R.; Creaven, B. S.; Walsh, M.; McCann, M.; Egan, D. \& Kavanagh, K. (2007). Mechanism of action of coumarin and silver(I)-coumarin complexes against the pathogenic yeast Candida albicans. Toxicology in Vitro, Vol. 21, No. 5, pp. 801-808, ISSN 08872333

Thomas, S. \& McCubbin, P. (2003). A comparison of the antimicrobial effects of four silvercontaining dressings on three organisms. Journal of wound care, Vol. 12, No. 3, pp. 101-107, ISSN 09690700

Tilaki, R. M.; Iraji zad, A. \& Mahdavi, S. M. (2006). Stability, size and optical properties of silver nanoparticles prepared by laser ablation in different carrier media. Applied Physics A: Materials Science \& Processing, Vol. 84, No. 1, pp. 215-219

Veratti, G. (1748). Osservazioni fisico-mediche intorno alla elettricità, Lelio della Volpe Bologna, Italy

Zhang, J.-P.; Chen, P.; Sun, C.-H. \& Hu, X.-J. (2004). Sonochemical synthesis of colloidal silver catalysts for reduction of complexing silver in DTR system. Applied Catalysis A: General, Vol. 266, No. 1, pp. 49-54, ISSN 0926-860X 


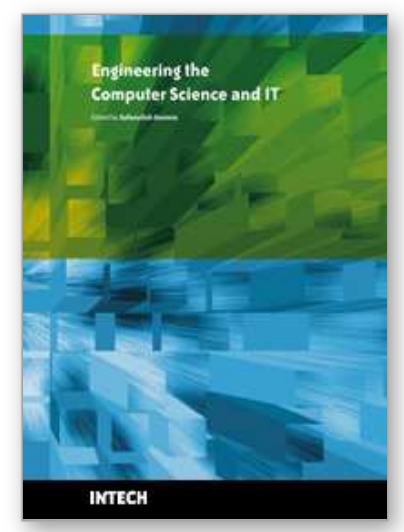

\section{Engineering the Computer Science and IT \\ Edited by Safeeullah Soomro}

ISBN 978-953-307-012-4

Hard cover, 506 pages

Publisher InTech

Published online 01, October, 2009

Published in print edition October, 2009

It has been many decades, since Computer Science has been able to achieve tremendous recognition and has been applied in various fields, mainly computer programming and software engineering. Many efforts have been taken to improve knowledge of researchers, educationists and others in the field of computer science and engineering. This book provides a further insight in this direction. It provides innovative ideas in the field of computer science and engineering with a view to face new challenges of the current and future centuries. This book comprises of 25 chapters focusing on the basic and applied research in the field of computer science and information technology. It increases knowledge in the topics such as web programming, logic programming, software debugging, real-time systems, statistical modeling, networking, program analysis, mathematical models and natural language processing.

\section{How to reference}

In order to correctly reference this scholarly work, feel free to copy and paste the following:

Kuo-Hsiung Tseng, Chih-Yu Liao, Der-Chi Tien and Tsing-Tshih Tsung (2009). Dissociation of Colloidal Silver into lonic Form through Membrane under Electric Field, Engineering the Computer Science and IT, Safeeullah Soomro (Ed.), ISBN: 978-953-307-012-4, InTech, Available from:

http://www.intechopen.com/books/engineering-the-computer-science-and-it/dissociation-of-colloidal-silver-intoionic-form-through-membrane-under-electric-field

\section{INTECH}

open science | open minds

\author{
InTech Europe \\ University Campus STeP Ri \\ Slavka Krautzeka 83/A \\ 51000 Rijeka, Croatia \\ Phone: +385 (51) 770447 \\ Fax: +385 (51) 686166 \\ www.intechopen.com
}

\author{
InTech China \\ Unit 405, Office Block, Hotel Equatorial Shanghai \\ No.65, Yan An Road (West), Shanghai, 200040, China \\ 中国上海市延安西路65号上海国际贵都大饭店办公楼 405 单元 \\ Phone: +86-21-62489820 \\ Fax: +86-21-62489821
}


(C) 2009 The Author(s). Licensee IntechOpen. This chapter is distributed under the terms of the Creative Commons Attribution-NonCommercial-ShareAlike-3.0 License, which permits use, distribution and reproduction for non-commercial purposes, provided the original is properly cited and derivative works building on this content are distributed under the same license. 